\title{
CARDIOVASCULAR CHANGES DEPENDING ON EXERCISING: STRENGTH EXERCISE OR NORDIC WALKING
}

\author{
Živilè Ščevinskaitė, Eugenijus Trinkūnas, Kristina Poderienė \\ Lithuanian Sports University, Kaunas, Lithuania
}

\begin{abstract}
Background. The aim of the study was to compare the acute training effect on the cardiovascular changes under influence of different kinds of health enhancing exercising.

Methods. Ten healthy males carried out two health promotion sessions by applying strength type exercising or Nordic-walk. Cardiovascular functional state was assessed before the training session and 30 minutes after the health promotion session by continuous 12-lead ECG recording while performing a Roufier Test (30 squats per $45 \mathrm{~s}$ ) and by measuring arterial blood pressure.

Results. A significant increase in the heart rate at rest was registered after the training session both after the gym training and after Nordic-walking session and reduced diastolic blood pressure values were recorded at rest and after the exercise stress test. If prior to the exercise sessions transient ischemic episode in some subjects was registered, after the training sessions the ischemic episodes were less expressed.

Conclusion. Comparing the Nordic walking exercise effects with the effects of strength training exercising during the training session, less increased heart rate and systolic blood pressure were observed; a significantly higher decrease in the diastolic blood pressure, and a significantly lower degree on the short-term effects of functional ischemic myocardium were recorded.
\end{abstract}

Keywords: Nordic walking, strength exercise, cardiovascular system.

\section{INTRODUCTION}

I n many countries one of the most common causes of death is cardiovascular diseases. Morbidity due to cardiovascular system diseases is the most common health problem among middle-aged and elderly people. Physical activity and exercising is important not only for the performance of daily activities, but also for health promotion (Karmisholt \& Gøtzsche, 2004). Nowadays one of physical activity forms with growing popularity is Nordic walking. It is a way of walking using special walking poles. The basic difference between Nordic walking and normal walking is that in Nordic walking technique special poles adapted to the walker's height are used (Figard-Fabre, Fabre, Leonardi, \& Schena, 2010). Nordic walking claims a number of additional health benefits over normal walking such as

increased oxygen uptake (11\%), heart rate (HR) $(8 \%)$ and calorie expenditure (18\%) (Tschentscher, Niederseer, \& Niebauer, 2013). There are some studies, which compared Nordic walking with jogging or fast walking. Nordic walking has the advantage in all cases (Tschentscher et al., 2013). Nordic walking is a safe way of increasing aerobic working capacity because people can choose the walking speed and stop exercising if they feel a discomfort (Stief et al., 2008). According to the same scientific research, Nordic Walking can be used for children, middle-aged or elderly people (Parkatti, Perttunen, \& Wacker, 2012) as well as pregnant women (Korsten-Reck, 2010). Thus, Nordic walking is a widely adaptable form of physical activity. Although there is no doubt in the benefit of Nordic walking, comparative studies 
that evaluated Nordic walking and other health promoting effects of exercise on the cardiovascular system have not been executed. The aim of this study was to compare the acute training effect on the cardiovascular changes during different kinds of health enhancing exercising.

\section{METHODS}

In order to proceed with the research, permission has been requested and was it granted by the Committee of Bioethics of Lithuanian University of Health Sciences. The research was performed in the Kinesiology Laboratory in Lithuanian Sports University. Ten volunteers participated in the study (males, age $-46.3 \pm 1.2$ ), who regularly exercised for health in a sports club. All participants were relatively healthy, non-complainant of cardiovascular dysfunction, with a permission from the doctor to participate in health strengthening exercises. They were randomly divided into two groups and participated in health strength exercise with a threeday break between them. The first group exercised in the gym and after a three-day break they did Nordic walking exercises. The second group, on the contrary, had Nordic walking first, and then they exercised in the gym doing strength training exercises after a three-day break.

The two testing procedures, i.e. before the training session and 30 minutes after the health promotion session were performed. Functional state assessment of the cardiovascular system was assessed by continuous 12-lead ECG recording while performing a Roufier Test (30 squats per $45 \mathrm{~s}$ ), and measuring the arterial blood pressure (ABP) every single minute.

Statistical analysis was performed using Microsoft Office Excel and SPSS software packages. In order to identify the differences between two independent groups we used the Mann-Whitney $U$ test, between three related groups - Friedman test. The results are represented as arithmetic mean \pm the standard error of the mean (SEM). Statistical significance was accepted when $p<.05$.

\section{RESULTS}

The results of the research are presented in Figures 1-4. They represent the cardiovascular functional state changes while comparing their dynamics during Roufier Test.

Figure 1 presents the HR changes during testing procedures. The HR before using Roufier Exercise Test in the relative repose was $73.1 \pm 2.16$ beats/ min. After repeating the exercise in the gym the test registered statistically significantly $(p<.05)$ higher HR values. Average HR was $100.9 \pm 2.46$ beats/ min. At rest after Nordic walking HR was also significantly higher than before walking (103.2 \pm 2.36 beats $/ \mathrm{min}, p<.05)$. After the training, there was no difference between the Nordic walking and strength exercise in HR $(p>.05)$. There were no statistically significant differences between the groups. Other HR assessed values recorded using

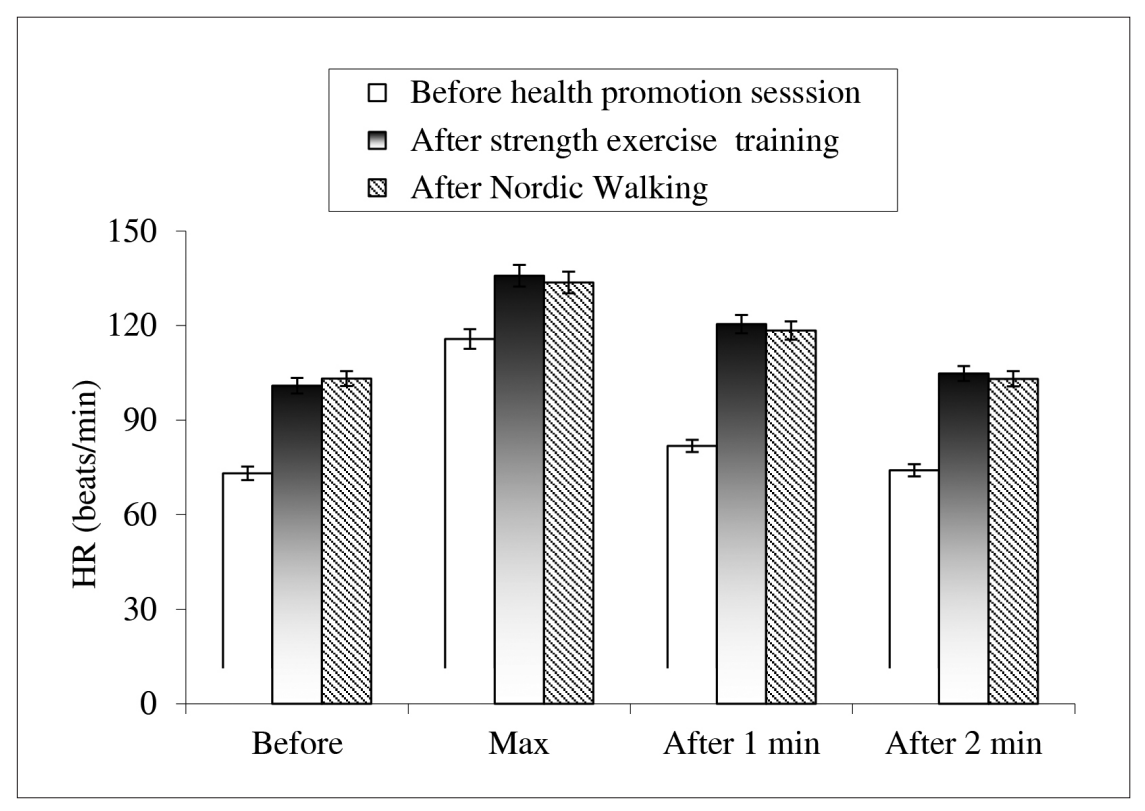

Figure 1. HR changes while performing Roufier Exercise Test 
Roufier exercise test were statistically significantly $(p<.05)$ higher than it was observed before the training session.

Figure 2 presents the data of ST-segment depression at relative rest and maximal values registered during Roufier Exercise Test. Statistically significant results $(p<.05)$ were found comparing the maximum ST-segment depression values which were registered in the squat. Comparison of the values before and after exercise showed significant $(p<.05)$ differences between them. Before walking ST-segment depression maximal value was $0.35 \pm$ $0.6 \mathrm{mV}$, then it decreased to $0.12 \pm 0.5 \mathrm{mV}$. There was also a significant difference comparing the exercise in the gym and Nordic walking. After the Nordic walking ST-segment depression was
$0.12 \pm 0.5 \mathrm{mV}$, and after the exercise in the gym the averaged values were higher, i.e. $0.29 \pm 0.5 \mathrm{mV}$ $(p<.05)$. Figure 3 shows the results of systolic ABP changes in response to Roufier Test, which confirms its increase due to the physical strain as well as full recovery in two minutes of rest. The results of the study revealed some changes in systolic ABP change features. After the exercise (Nordic walking and exercise in the gym) systolic ABP was reduced, i.e. post-exercise hypotension was observed, but this difference was not statistically significant $(p>.05)$.

As it is presented in Figure 4, the diastolic ABP value before exercise at rest was $85 \pm 2.2 \mathrm{mmHg}$, after Nordic walking it was $79.3 \pm 2.3 \mathrm{mmHg}$, which demonstrated a significant increase $(p<.05)$.
Figure 2. ST-segment depression values registered before Roufier Exercise Test and during the exercising (30 squats per $45 \mathrm{~s}$ )

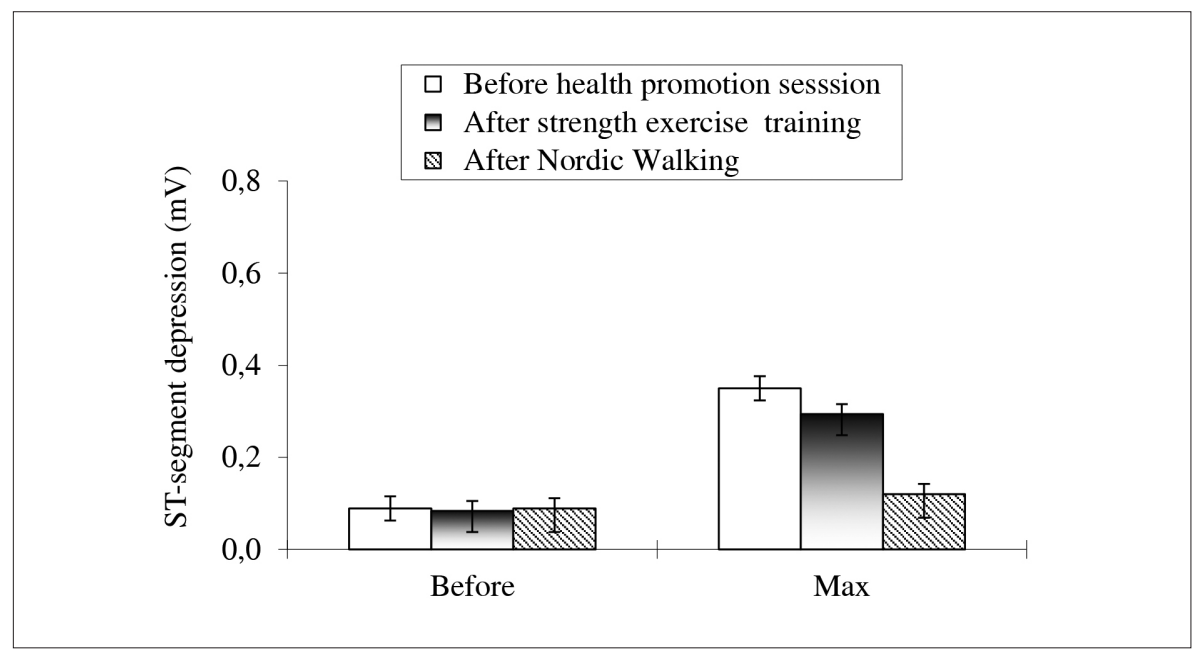

Figure 3. Diastolic ABP changes while performing Roufier Exercise Test

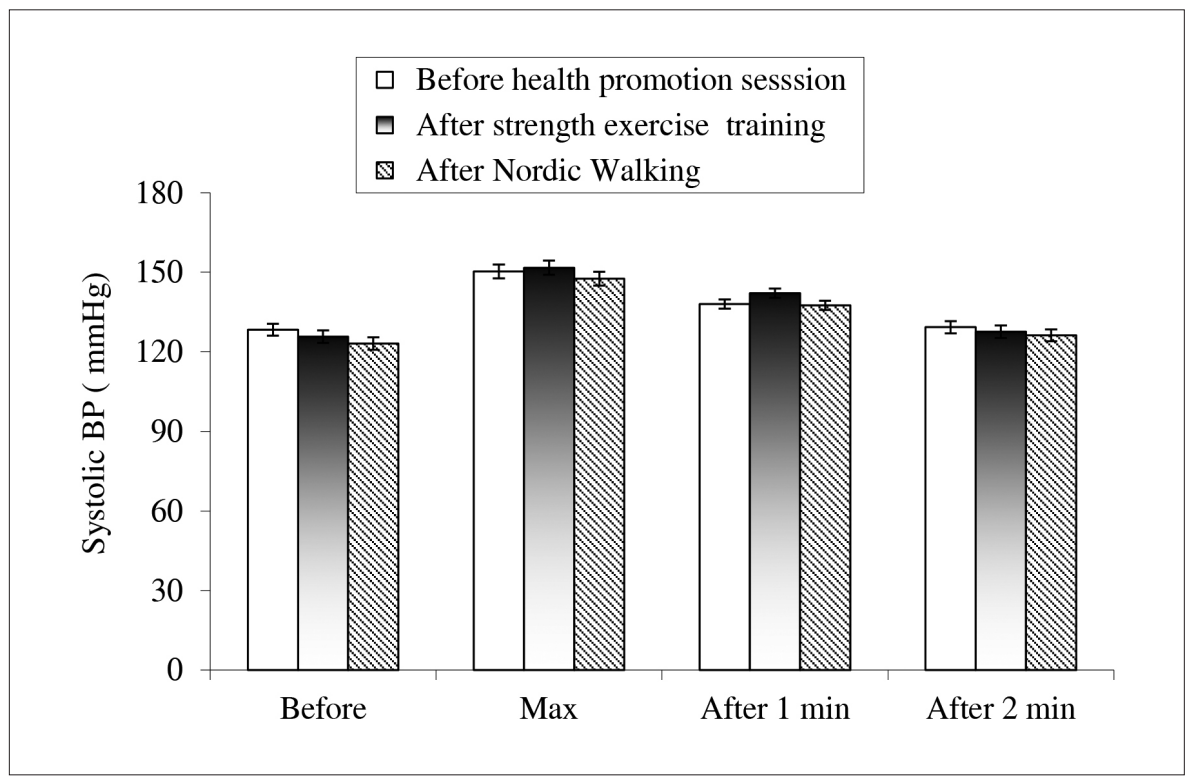




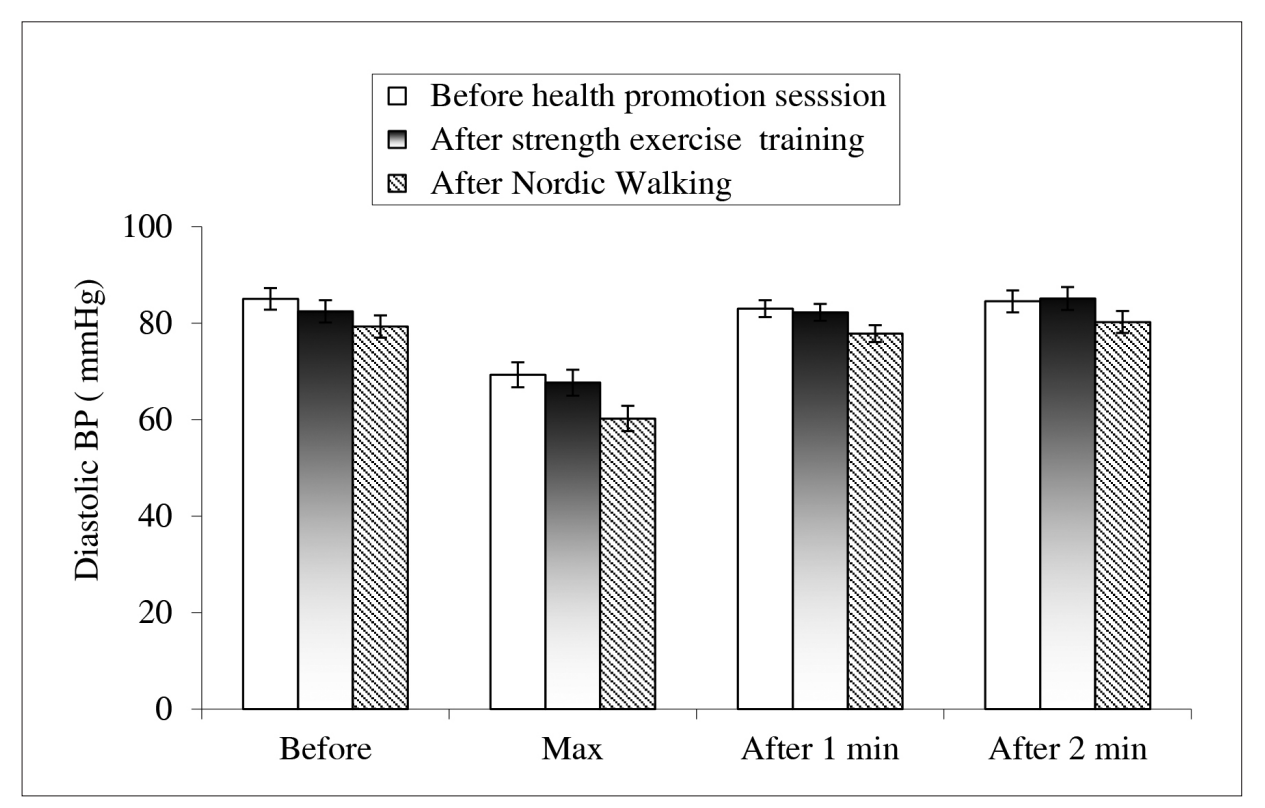

Figure 4. Diastolic ABP changes while performing

Roufier Exercise Test

There was no significant change at rest during the exercise test before and after exercise in the gym $(p>.05)$. The maximum value of diastolic blood pressure $(60.2 \pm 2.6 \mathrm{mmHg})$ after Nordic walking statistically significantly decreased comparing it with the blood pressure after the exercise in the gym $(67.7 \pm 2.6 \mathrm{mmHg})$ and the control group before walking $(69.3 \pm 2.6 \mathrm{mmHg})(p<.05)$.

\section{DISCUSSION}

The question which type of physical activity improves health most effectively remains relevant as a scientific and practical issue (Dunn, Lark, \& Fallows, 2013; Vainoras, 2004). In order to find an answer to this question, an evaluation and comparison of the early and long term adaptation has to be made. The majority of body's functional systems pick up the pace when carrying out a physical exercise, it also affects an increase of activity of most regulatory systems, therefore a lot of research can be carried out and scientific articles can convey different approaches.

Within the last few years a number of studies have been carried out on the effects of Nordic walking on different human body systems (Mikalacki, Cokorilo, \& Katić, 2011; Patanè, Marte, Dattilo, Grassi, \& Patanè, 2009; Simic, Hinman, Wrigley, Bennell, \& Hunt, 2010), although cardiovascular system has been much researched. This research was aimed at showing that Nordic walking is a safe and handy way of dealing with diseases caused by cardiovascular disease. Being easy to learn and of a reasonable price, Nordic walking could be a great way to improve health and is available for almost anyone. Considering the fact that we were evaluating the benefits of walking for the cardiovascular system of healthy individuals, we suggest that this type of exercise could be an alternative to gym training.

The results of the research have revealed that the functional state and change of the human body due to physical impact can be determined by electrocardiograms and vascular blood pressure values by taking a dozed physical impact. After taking dozed physical activity sample after training, the HR increases and an increase in systolic as well as a decrease in diastolic blood pressure can be observed. Short-term effects of functional ischemic episodes in myocardium could also be observed in persons with lower physical fitness. The research results confirm those of other researchers (Zachariene, 2012) presenting the results about changes due to the performed activity and energy loss. When considering the results, it is important to remember that they have been taken 30 minutes post training, thus they reflected the post workout state of the body that provokes the phenomenon of long term adaptation.

\section{CONCLUSION}

The benefit of Nordic walking comparing with the effects caused by strength exercising could be evidenced by the fact that when there was a less increase in heart rate, there was a significantly greater decrease in diastolic blood pressure, and smaller short-term functional ischemic episodes were registered during the dosed exercise test. 


\section{REFERENCES}

Dunn, S., Lark, S., \& Fallows, S. J. (2013). Identifying similar and different factors affecting long-term cardiac exercise rehabilitation behaviour modification between New Zealand and the United Kingdom. Journal of Physical Activity \& Health, 11(5), 1018-1024. PMID: 23799263.001

Figard-Fabre, H., Fabre, N., Leonardi, A., \& Schena, F. (2010). Physiological and perceptual responses to Nordic walking in obese middle-aged women in comparison with the normal walk. European Journal of Applied Physiology, 108(6), 1141-1151. doi: 10.1007/ s00421-009-1315-z

Karmisholt, K., \& Gøtzsche, P. C. (2005). Physical activity for secondary prevention of disease. Systematic reviews of randomised clinical trials. Danish Medical, 52(2), 90-94. PMID: 16009053

Korsten-Reck, U. (2010). Physical activity in pregnancy and in breast-feeding period in obese mothers. (2010). Zeitschrift für Geburtshilfe und Neonatologie, 214(3), 95-102. doi: 10.1055/s-0030-1254139

Mikalacki, M., Cokorilo, N., \& Katić, R. (2011). Effect of Nordic walking on functional ability and blood pressure in elderly women. Collegium Antropologicum, 35(3), 889-894. PMID: 22053573

Parkatti, T., Perttunen, J., \& Wacker, P. J. (2012). Improvements in functional capacity from Nordic walking: A randomized-controlled trial among elderly people. Journal of Aging and Physical Activity, 20(1), 93-105. PMID: 21949243
Patanè, S., Marte, F., Dattilo, G., Grassi, R., \& Patanè, F. (2010). Exercise-induced ST-segment depression in inferior leads during treadmill exercise testing and coronary artery disease. International Journal of Cardiology, 145(3), 88-91. PMID: 19176254.001

Simic, M., Hinman, R. S., Wrigley, T. V., Bennell, K. L., \& Hunt, M. A. (2011). Gait modification strategies for altering medial knee joint load: A systematic review. Arthritis Care Research, 63(3), 405-426. doi: 10.1002/ acr.20380

Stief, F., Kleindienst, F. I., Wiemeyer, J., Wedel, F., Campe, S., \& Krabbe, B. (2008). Inverse dynamic analysis of the lower extremities during Nordic walking, walking, and running. Journal of Applied Biomechanics, 24(4), 351-359.

Tschentscher, M., Niederseer, D., \& Niebauer, J. (2013). Health benefits of Nordic walking. A systematic review. American Journal of Preventive Medicine, 48(21), 7684. doi: 10.1016/j.amepre.2012.09.043

Vainoras, A. (2004). Fizinių krūvių veikimo žmogaus organizmo pokyčiu vertinimo kompleksinis modelis. In Kineziologijos pagrindai: mokomoji knyga (pp. 195206). Kaunas: KMU leidykla.

Zacharienė, B. (2012). Centriniu ir periferiniu širdies ir kraujagysliu sistemos funkciniu rodikliu kaitos ypatybès, atliekant globalaus, regioninio pobūdžio bei lokaliuosius fizinius krūvius (Daktaro disertacija). Kaunas: Lietuvos kūno kultūros akademija. Retrieved from htttp://lnb.libis. 1t/simpleSearch.do?pageSize $=1 \&$ order $=$ true $\&$ BI001 